\title{
A Graduação em Saúde Coletiva: um Debate ou uma Realidade?
}

\section{Graduation in Collective Health: Debate or Reality?}

Lilian Koifman ${ }^{I}$ Lina Nunes Gomes ${ }^{I I}$

\begin{abstract}
A pergunta do título torna-se muito pertinente em nossa atual situação, pois há um movimento nacional e internacional de abertura de graduações em Saúde Coletiva, havendo grande discussão sobre o tema. Muitas universidades estão preparando esses cursos: o panorama é de cerca de dez cursos abertos ou em vias de iniciar suas atividades no próximo ano.

A questão agora é posicionar-se contra ou a favor da abertura dessa graduação no cenário que está se formando ou tomar esse dado como uma realidade.

Alguns dos cursos abertos têm procura, com boa relação candidato/vaga, mas a maioria ainda não apresenta grande disputa, existindo até um caso em que há mais vagas do que alunos inscritos para o vestibular.

Diante desse panorama, será que ainda caberia um posicionamento contra ou a favor da abertura dessa graduação? Ou será pertinente entender as diversas propostas, perfis e - por que não - seus equívocos?
\end{abstract}

A justificativa para a abertura dos cursos tem girado em torno de algumas referências, como o documento da Organização Pan-Americana de Saúde, de $2000^{1}$, que define dez serviços essenciais de saúde pública, ou Funções Essenciais de Saúde Pública.

Além dessa justificativa, temos ainda, acirrando mais recentemente o debate, o Projeto Reuni, do Ministério da Educação, que exerce pressão para a abertura de novas graduações nas universidades públicas, com a intenção de abrir novas vagas de ensino superior. Ainda temos como pano de fundo as Diretrizes Curriculares Nacionais, que trazem uma formação mais abrangente do profissional de saúde, abrindo uma brecha para esse tipo de curso ${ }^{2-10}$.

As Diretrizes Curriculares Nacionais abrem bastante a formação dos profissionais de saúde para uma formação mais voltada ao SUS. Nela, o profissional deve ter uma visão e uma escuta mais voltadas para um conceito ampliado de saúde, não meramente a ausência de doença, e desenvolver uma clínica mais abrangente, para além das instituições de assistência.

No caso da graduação em Medicina, temos como competências e habilidades gerais, que se interligam com o campo da Saúde Coletiva: atenção à saúde, comunicação, liderança, administração e gerenciamento e educação permanente. Tais competências e habilidades estão presentes na maioria das Diretrizes Curriculares dos cursos de graduação na área de saúde e também têm sido utilizadas para a graduação em Saúde Coletiva.

Essa graduação teria como finalidade suprir uma suposta crescente demanda do mercado por profissionais aptos a atuar no planejamento, gestão e execução de ações em Saúde Coletiva, apesar de isso estar descrito como habilidades gerais de vários profissionais de saúde. E ainda: "contribuir para a definição de uma política inovadora, mas fundamentalmente contemporânea, de formação de profissionais da área da saúde ou com forte atuação neste setor. Neste sentido, visa amparar o setor da saúde com a formação de um profissional demandado, mas inexistente no âmbito da graduação, em concordância com as políticas

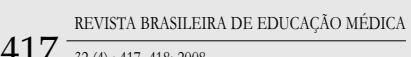

${ }^{I}$ Universidade Federal Fluminense, Rio de Janeiro, Brasil. Editora Associada da Revista Brasileira de Educação Médica.

"Universidade Federal Fluminense, Rio de Janeiro, Brasil. 
públicas dos setores da Educação Superior e do Sistema Único de Saúde ${ }^{3 \prime}$.

O perfil do egresso seria de um profissional com formação generalista, humanista, crítica e reflexiva. Qualificado para atender as necessidades sociais de saúde e gerente de processos coletivos de trabalho em saúde, fundamentado em princípios humanísticos, éticos e estéticos. Capaz de realizar ações de vigilância, planificação, gestão, controle, avaliação, auditoria, além de intervenções sociais organizadas dirigidas a promoção, proteção, comunicação e educação em saúde $\mathrm{e}^{2-10}$.

Não seriam estas competências/habilidades/atitudes que deveriam ser trabalhadas nas graduações de Ciências da Saúde em geral? Será possível transformar um programa que devia fazer parte de várias graduações em uma só graduação? Não haveria um esvaziamento das outras graduações em Ciências da Saúde?

Existe o temor de que a criação desses cursos provoque uma tendência a aumentar as lacunas já presentes da participação da Saúde Coletiva nas outras graduações. O remanejamento de professores e o deslocamento de esforços criam o risco de empobrecimento do campo pela perda de duas de suas características fundamentais: a interdisciplinaridade e a multiprofissionalidade ${ }^{4}$.

Especificamente no ensino médico, corre-se o risco de, após tantos anos de discussão que desembocou na construção das diretrizes, perder espaço teórico em decorrência do deslocamento de professores para essa graduação. Se, na atualidade, o trabalho nos cursos de Medicina na área de Saúde Coletiva ainda é difícil, na perspectiva de melhor interação com os alunos e melhor troca com outros saberes, talvez aumentemos o risco de diminuir a proporção de disciplinas desse campo.

Além disso, será que o SUS precisa de mais uma categoria profissional? Ou não precisaria dos profissionais existentes, mas com um novo perfil de atuação, novas competências, novos compromissos políticos, técnicos e profissionais ${ }^{4}$ ?

Desde a década de 1980, o campo da Saúde Coletiva tem relegado as graduações a um segundo plano e privilegiado as pós-graduações na área. Com isso perdeu-se um espaço vital de formação dos profissionais de saúde que não será retomado apenas com a inauguração de uma graduação. Existe o risco de que o campo se isole ainda mais.

Do ponto de vista de um estudante que deseja se formar nessa área, seria muito bom ter um curso onde ele só estudaria e aprenderia conteúdos com os quais se identifica e que lhe agradam. Mas quantos estudantes têm esse perfil? Quan- tos estudantes saídos do ensino médio conhecem o campo da Saúde Coletiva?

Ainda sob a ótica desse estudante, ele teria mesmo que enfrentar tantos anos para finalmente trabalhar na área? Façamos as contas: seis anos de graduação, um ou dois anos de residência e/ou mestrado e, em alguns casos, quatro anos de doutorado. Não teria esse aluno um percurso mais objetivo se pudesse fazer um curso de cerca de quatro anos e se formar em Saúde Coletiva? E, a partir dessa nova profissão, teria mais oportunidade de aprofundar os conhecimentos do campo sem a necessidade de cursar tantas disciplinas que ficarão esquecidas e abandonadas após sua entrada no campo de Saúde Coletiva. Para atingir tais habilidades e competências, não terá que percorrer a maratona de obstáculos que hoje enfrenta.

Há muitas coisas a pensar e poucas respostas ainda. $\mathrm{O}$ momento é muito rico para observar as experiências recémnascidas, pensar sobre elas e produzir novos artigos sobre o tema.

\section{REFERÊNCIAS}

1. Organização Pan-Americana da Saúde. Funções Essenciais em Saúde Pública. CE 126/17 (Port.). 27 de Abril de 2000.

2. Universidade Federl do Rio de Janeiro. Proposta de Curso de Graduação em Saúde Coletiva. Maio de 2003.

3. Universidade Federal do Rio Grande do Sul. Políticas e Sistemas de Saúde - Proposta de Bacharelado em Saúde Coletiva. 15 de Agosto de 2008.

4. Universidade Federal do Acre. Curso de Graduação em Saúde Coletiva; 2008.

5. Universidade Federal Minas Gerais. Bacharelado em Análise de Sistema e Serviços de Saúde; 2008.

6. Universidade Federal da Bahia. Curso de Graduação em Saúde Coletiva; 2008.

7. Universidade Federal Rio Grande do Norte. Curso de Gestão de Sistemas e Serviços de Saúde; 2009.

8. Universidade de Brasília. Curso de Graduação em Saúde Coletiva. 2008

9. Universidade Federal de Mato Grosso. Curso de Graduação de Saúde Coletiva. 2008.

10. Universidade Federal do Pará. Curso de Graduação de Saúde Coletiva; 2008.

11. Almeida M. "É tempo de termos uma graduação em saúde coletiva?" Exposição no Painel realizado durante o VII Congresso Brasileiro de Saúde Coletiva em Brasília no dia 1 ago. 2003. 